Article

\title{
Advanced Dimming Control Algorithm for Sustainable Buildings by Daylight Responsive Dimming System
}

\author{
In-Tae Kim ${ }^{1}$, Yu-Sin Kim ${ }^{1}$, Hyeonggon Nam ${ }^{2}$ and Taeyon Hwang ${ }^{2, *}$ \\ 1 Lighting Platform Research Center, Korea Photonics Technology Institute (KOPTI), Gwangju 61007, Korea; \\ itkim@kopti.re.kr (I.-T.K.); yskim@kopti.re.kr (Y.-S.K.) \\ 2 School of Architecture, Chosun University, Gwangju 61452, Korea; hyeonggon.nam@chosun.kr \\ * Correspondence: taeyon.hwang@chosun.ac.kr
}

Received: 17 October 2018; Accepted: 5 November 2018; Published: 7 November 2018

\begin{abstract}
This study aims to evaluate the accuracy and energy savings of a daylight responsive dimming system (DRDS) when considering the influence of indirect illuminance. In the case of the existing DRDS, during the calibration process of each luminaire, the other luminaires were turned off to detect the illuminance of both the luminaire and the incoming daylight. However, the work plane illuminance under the luminaires was affected by the indirect illuminance from the other luminaires. The final work plane illuminance would thus be higher than the target illuminance during real system operation. To improve the accuracy and energy savings of the DRDS, an improved dimming control algorithm was applied to the DRDS when considering the influence of indirect illuminance. The real-time power consumption and accuracy of the target illuminance of the DRDS when considering the influence of indirect illuminance in a full-scale mock-up was measured and analyzed (for 23 days, from 22 June to 18 July 2018). As a result, the average accuracy of the target illuminance was $98.9 \%$ (SD $0.5 \%$ ), and the average saving in lighting energy was $77 \%$.
\end{abstract}

Keywords: LED dimming system; energy savings; daylight; indirect illuminance

\section{Introduction}

\subsection{Study Objective}

Since the 1997 Kyoto Protocol to the United Nations Framework Convention on Climate Change, the international community has been pursuing various policies to cope with climate change. The Republic of Korea has announced its greenhouse gas emissions reduction goals. To fulfill these goals, research and development has been actively carried out to reduce the greenhouse gas emissions and energy consumption in each field. In the field of architecture, which accounts for $25 \%$ of the total greenhouse gas emissions in the Republic of Korea, for example, a zero-energy building activation policy is being implemented to reduce the energy consumption of buildings by more than $90 \%$ when combining energy consumption and production [1]. To realize a zero-energy building, it is necessary to improve the efficiency of the facilities used in the building and to actively utilize renewable sources of energy. Among the various facilities of a building, the lighting installation occupies a relatively high proportion of about $20 \%$ of the total energy used [2]. To reduce the energy consumption of a lighting installation, LED luminaires with the advantages of high efficiency and a long life are used. In addition, studies were implemented to increase daylight availability and daylight factor through architectural design [3-8]. To further reduce the energy consumption of the lighting, a DRDS that utilizes daylight incident to an indoor area is typically used. 
The DRDS predicts the work plane illuminance by measuring the daylight incident to the indoor area through a photosensor installed on the ceiling or in the luminaire itself. If the predicted work plane illuminance exceeds the set target illuminance, the luminaire is turned off, and if it does not meet the target illuminance, the luminaire is dimmed based on the insufficient illuminance value. According to previous research, the saving in lighting energy achieved through daylight responsive dimming is about $60-80 \%$ on average [9]. This saving is a theoretical value that requires an accurate prediction of the work plane luminance, and precise control of the dimming. With a conventional DRDS, it is difficult to accurately predict the work plane illuminance, and the theoretical saving in lighting energy is not achieved when applying a simple dimming control algorithm. The simple dimming control algorithm applied to a conventional DRDS uses a direct illuminance learning method, which learns the work plane illuminance value of only a single point, and the value of a photosensor attached to the luminaire according to the available dimming level. This learning method is not suitable because an actual luminous environment is indirectly influenced by many luminaires at the same time. Therefore, in this study, a dimming control algorithm was developed that considers the indirect illuminance affecting the work plane illuminance as a way to improve the energy saving of the DRDS, and the target illuminance accuracy and saving in lighting energy were analyzed. The term of "indirect light" is generally used to indicate light reflected from non-emitting surfaces. In this paper, the term of "direct light" was used to indicate incident light from a specific luminaire to the work plane at a position directly under the specific luminaire. Also, the term of "indirect light" was used to indicate incident light from the other luminaires except the specific luminaire to the work plane at a position directly under the specific luminaire.

\subsection{Previous Research}

Several previous studies have analyzed the accuracy and energy saving of a DRDS. Al-Ashwal and Budaiwi (2011) investigated the energy performance of office buildings resulting from an integration of daylight and artificial lighting in hot climates according to the window design, including the window area, height, and glazing type. The results showed that as much as a 35\% reduction in lighting energy consumption can be achieved using daylight and artificial lighting integration [10]. Fernandes et al. (2013) evaluated the lighting energy saving of split-pane electrochromic (EC) windows controlled to satisfy key visual comfort parameters. Using Radiance lighting simulation software, the interior illuminance and luminance levels were computed for a south-facing private office illuminated by a window split into two independently controlled EC panes. Depending on the work plane illuminance for which the electrochromics were controlled, the energy savings ranged from $43 \%$ to $67 \%$ [11]. Caicedo et al. (2011) proposed a control method for achieving a target illuminance at the workspace plane using illuminance measurements from light sensors situated on the ceiling, as well as additional prior information from a sensor calibration. The proposed method achieved $10 \%$ less power savings on average than when the light sensors were located at the workspace plane [12]. Yoo et al. (2014) calculated the distribution of daylight illumination into an office, as well as the dimming ratios for individual control of LED lights using light simulation software. As a result, the power consumption of electrical lighting was reduced by $40-70 \%$ depending on the season and weather conditions [13]. Gentile and Dubois (2017) investigated the effectiveness of lighting control systems in office rooms located in Lund, Sweden. This study used simulations based on the actual occupancy data. The simulations focused on the portion of standby energy use on the total lighting energy use. The results showed that the standby energy use accounts for about $30 \%$ of the total lighting energy use, but it can increase up to $55 \%$ in extreme cases [14]. Nagy et al. (2015) presented an occupant-centered lighting control strategy and its successful implementation through a case study. A double-blind occupancy study was conducted, and the system performed as intended, adapting well to the occupants and achieving significant energy savings. The best result achieved was a $37.9 \%$ energy saving compared to the baseline mode, and 73.2\% compared to the worst-case situation, for an all-day lighting mode [15]. Gentile et al. (2016) presented the results of a monitoring study according to four different lighting 
control systems (a manual switch at the door, a presence detector, daylight dimming with an absence detector, and an LED task lamp). The energy performance of the manual switch with an absence detector was $75 \%$. The daylight-linked lighting control systems achieved only slightly higher savings $(79 \%)$ owing to the relatively high standby losses. The desk lamp achieved an energy saving of 97\% [16]. Kaminska and Ożadowicz (2018) evaluated reduced energy consumption from lighting in non-residential buildings equipped with KNX. The energy savings of offices were $28 \%$, and in educational buildings, energy savings totaled $24 \%$ [17].

In a previous study related to lighting control according to occupancy patterns and daylight, Yun et al. (2012) reported field survey results on the illuminance distributions, occupancy, and lighting use patterns, as well as the resulting lighting energy demand. No significant relationships were found between the available daylight and the use of lighting by the occupants. The lighting use patterns are significantly related to the occupancy patterns [18]. Pandharipande and Caicedo (2011) considered an energy-efficient illumination control design of LED-based lighting systems in office spaces. The goal of this study was to determine the optimum dimming levels of the LED sources to minimize the power consumption while rendering a uniform illumination at a given illumination level in occupied workspace regions, and a minimum illumination level of the lower value in unoccupied regions, while taking the daylight distribution over the workspace plane into account. As a result of this study, the power saving was $55-57 \%$ according to an overlap in occupancy [19].

Other previous studies suggested the use of a dimming control algorithm when considering indirect illuminance. Wang and Tan (2013) developed an illumination control for LED systems based on a neural network model and energy optimization algorithm when considering indirect illuminance. This study developed a dimming control algorithm considering indirect illuminance; however, the dimming control algorithm of this study can be applied to the DRDS, whereas the dimming control algorithm of our study cannot be applied to the DRDS [20]. Choi et al. (2016) suggested an "indirect illuminance" concept (method B) to improve the system performance and predict the potential savings in the lighting energy of a system. Certain inherent problems caused by the open-loop proportional control algorithm used were identified, and the energy saving potential of this method was $36.9-73.8 \%$ [21].

In a previous study related to predicting indoor illuminance by daylight, Yun and Kim (2018) developed the algorithm of the calculation formula from sky luminance distribution to vertical illuminance and indoor illuminance. Yun and Kim proposed a method to analyze the sky conditions using HDRI with a CCD camera [22]. Park et al. (2011) developed the improved closed-loop proportional control algorithm for the integrated systems to predict the varying correlation of photosensor signal to daylight work plane illuminance according to roller shade height and sky conditions for the improvement of the system accuracy [23].

In addition, Parise and Martirano (2013) suggested a criterion for evaluating the yearly daylight impact on the energy saving of internal lighting according to the daylight availability, the lighting system layout, and the control system arranged using a daylight lumen method [24]. Ul Haq et al. (2014) reviewed various existing technologies used for lighting control according to the input parameters, their control method, the control algorithm, the cost of installation, and the complexity of commissioning, among other factors. This study aimed at investigating the various control system types, the development of their associated technologies, the saving reported from their application, and the factors affecting their performance [25].

In summary, previous studies have examined the energy savings of DRDS; however, most of the studies have used a direct illuminance learning method or a simulation case study. Therefore, in this study, the real-time power consumption and target illuminance accuracy of the DRDS when considering the influence of indirect illuminance on a full-scale mock-up were measured and analyzed. 


\section{Daylight Responsive Dimming System (DRDS)}

\subsection{System Works of Conventional DRDS}

A DRDS analyzes the sky conditions through an external solar radiation sensor, as shown in Figure 1, and measures the amount of incident daylight into the room through a photosensor attached to the luminaire. Based on the measured amount of incident daylight in the photosensor, the work plane illuminance is predicted through the slope of the pre-learned photosensor/work plane illuminance. To consistently maintain the work plane at the target illuminance and save energy, if the predicted work plane illuminance exceeds the set target illuminance, the luminaire is turned off, and if it does not meet the target illuminance, the luminaire is dimmed based on the insufficient illuminance value. The photosensors can detect the difference between daylight and electric lighting by comparing the initial photosensor value and final photosensor value after maintaining the work plane. When the amount of incident daylight changes, photosensors can detect only the changed amount of incident daylight based on the detected difference between daylight and electric lighting.

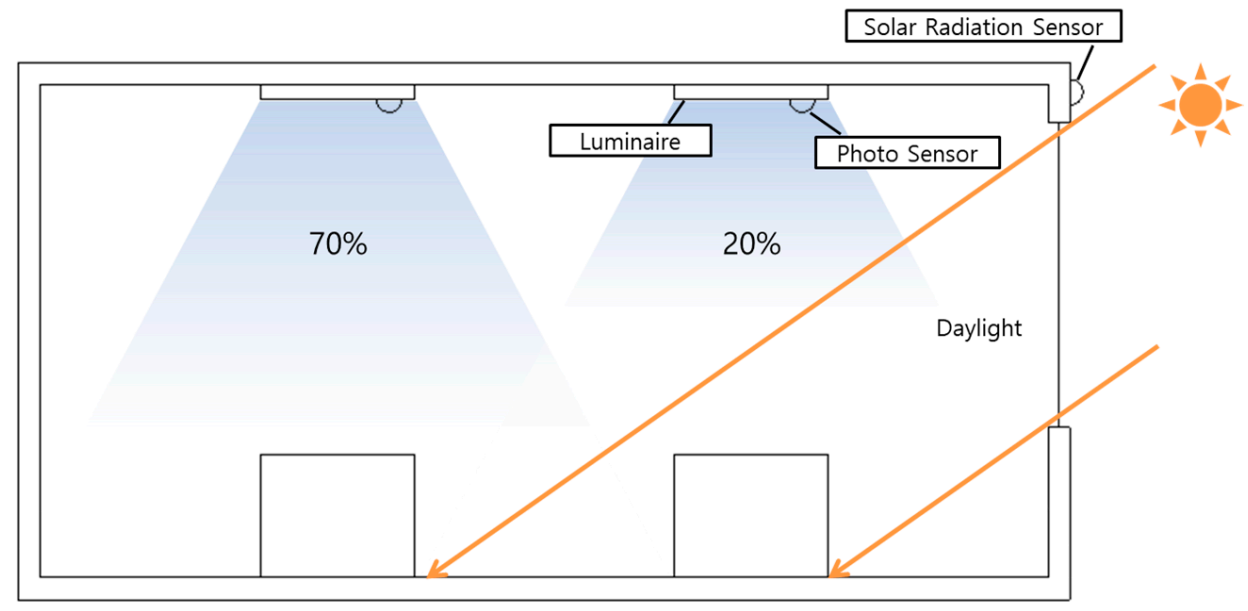

Figure 1. Concept of the daylight responsive dimming system (DRDS).

\subsection{Conventional Dimming Control Algorithm (Direct Illuminance Learning Method)}

The direct illuminance learning method is a method for learning the work plane illuminance and the photo-sensor value according to the dimming level of the luminaire at night. As shown in Figure 2, an illuminance meter is installed at a position directly under the luminaire. The values of the work plane illuminance directly under the luminaire and the photosensor are both logged according to the dimming level of each luminaire. For example, when learning about luminaire 1, the values of the work plane illuminance directly under luminaire 1 and the photosensor attached to luminaire 1 are logged according to the dimming level of the luminaire. At this time, the values of the work plane illuminance directly under luminaire 2 and the photosensor attached to luminaire 2 are not learned. Likewise, when learning about luminaire 2 , only the values of the work plane illuminance directly under luminaire 2 and the photosensor attached to luminaire 2 are learned. 


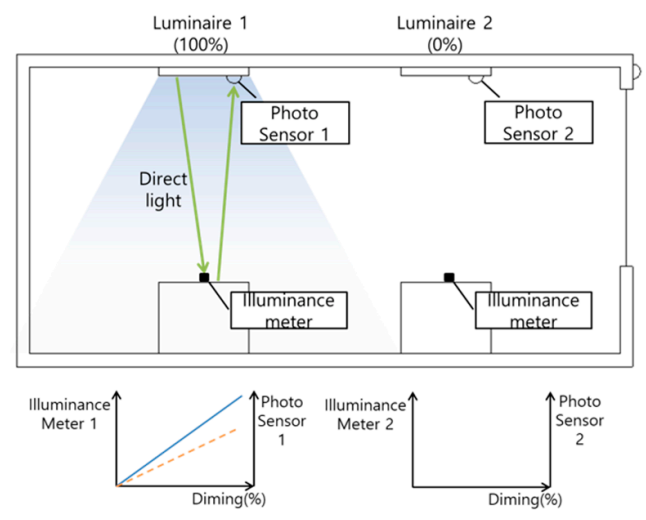

(a)

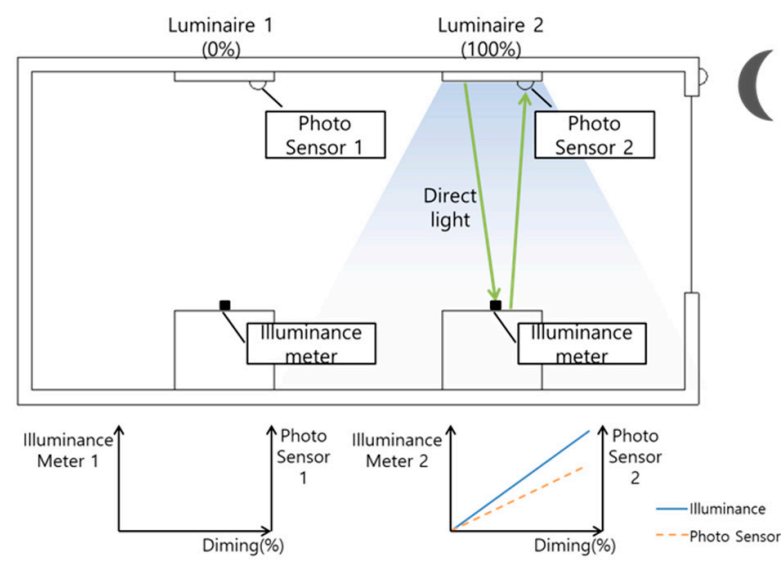

(b)

Figure 2. System process of direct illuminance learning methods: (a) learning process for luminaire 1,

(b) learning process for luminaire 2.

The direct illuminance learning method is relatively simple and is able to learn the necessary information in a short period of time. However, when applied to an actual luminous environment, the work plane illuminance exceeds the target illuminance owing to the influence of indirect illuminance by the other luminaires (Figure 3).

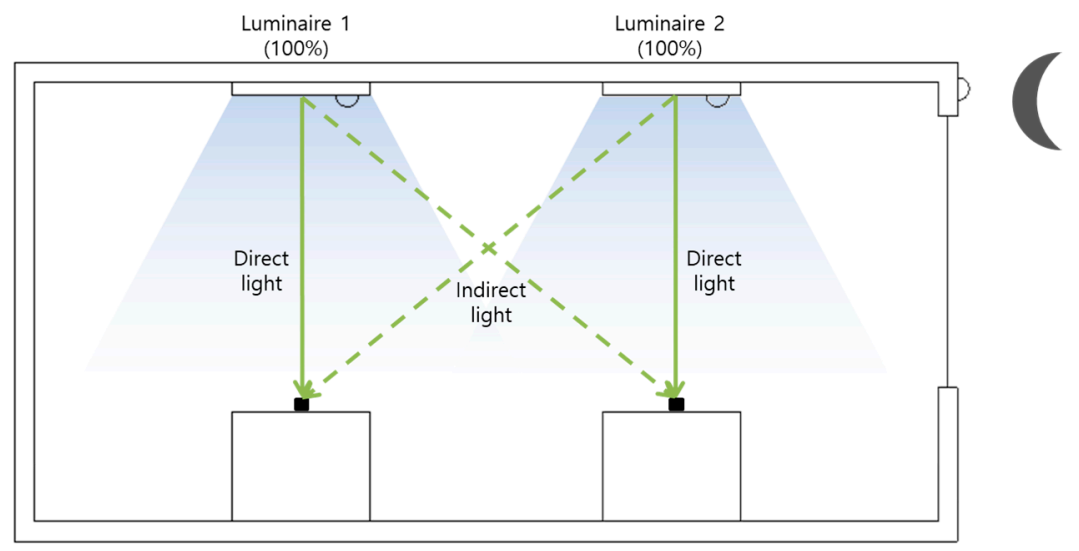

Figure 3. Actual luminous environment affected by direct and indirect illuminance.

If the photosensor attached to the luminaire recognizes that the work plane illuminance has been exceeded, the luminaires are dimmed by the amount of target illuminance exceeded. The direct illuminance learning method algorithm does not recognize whether the excess illuminance is influenced by the indirect illuminance of the other luminaires, however. For this reason, the luminaires are excessively dimmed. As shown in Figure 4, the DRDS applying a direct illuminance learning method maintains the target illuminance by repeating the process of exceeding and not exceeding the target illuminance. Depending on the particular case, when the target illuminance is converged after a repetition of about 10 to 30 times, if the system is set for control once per minute, the lighting energy is over-consumed, and the occupant may feel visual discomfort for about 10 to 30 min (Figure 4a). In addition, when the indirect illuminance component is larger than the direct illuminance component, the illuminance diverges without convergence to the target illuminance, and the target illuminance cannot be maintained (Figure $4 b$ ).

For example, assuming that the direct illuminance directly under an individual luminaire (when the dimming level is $100 \%$ ) is $500 \mathrm{~lx}$, and the total amount of illuminance (direct + indirect) directly under an individual luminaire (when the dimming level is 100\%) is $1010 \mathrm{~lx}$, each luminaire will illuminate at $100 \%$ to maintain the target illuminance of $500 \mathrm{~lx}$. When all luminaires are turned on at 
100\%, the work plane illuminance reaches $1010 \mathrm{~lx}$, which exceeds $510 \mathrm{~lx}$. To reduce the illuminance, the luminaires are completely turned off and diverge without converging to the target illuminance (Figure 4b).

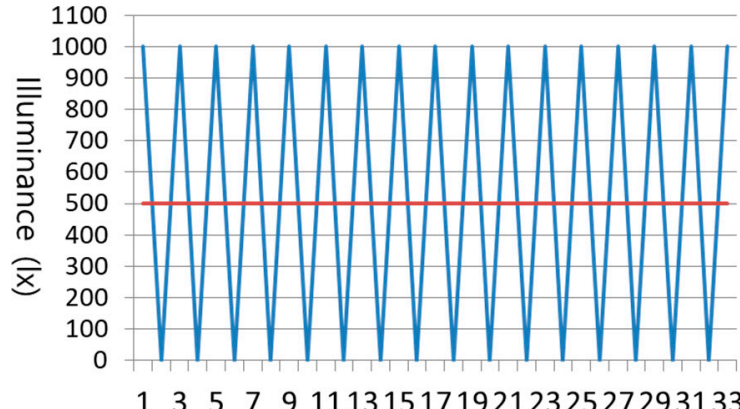

(Step)

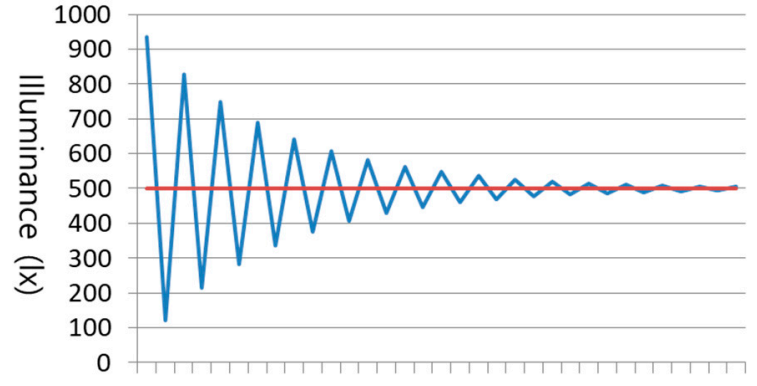

13579111315171921232527293133

(a)

(b)

Figure 4. Maintaining the target illuminance of the daylight responsive dimming system applying the direct illuminance learning method: (a) convergence and (b) divergence cases.

\subsection{Proposed Dimming Control Algorithm (Indirect Illuminance Learning Method)}

To solve the shortcomings of the direct illuminance learning method, this study proposes a learning method that considers the influence of indirect illuminance. Indirect illuminance learning is conducted at night when the daylight is not incident, as in a direct illuminance learning method. Unlike a direct illuminance learning method, the work plane illuminances of all points and the photosensor values of all luminaires are logged according to the dimming level per luminaire (Figure 5).

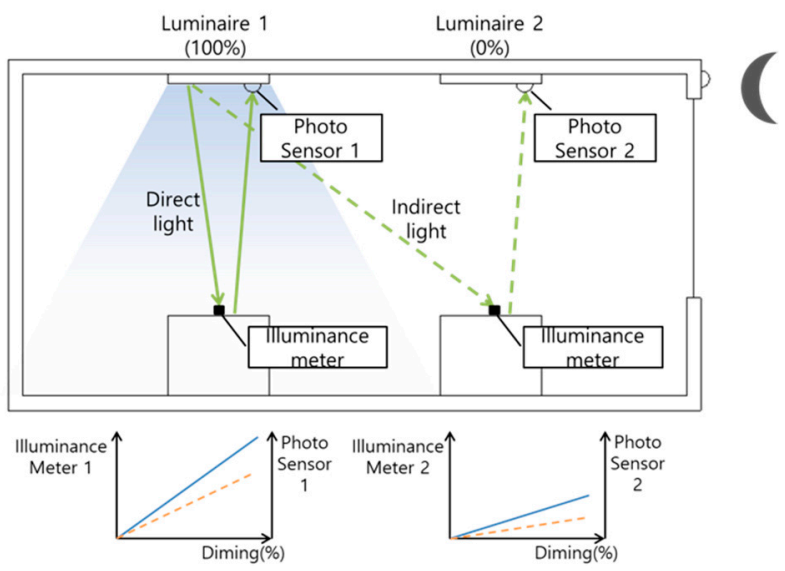

(a)

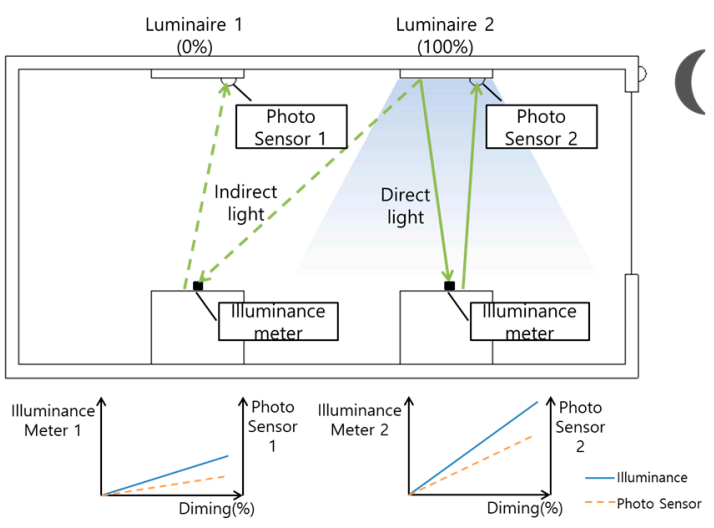

(b)

Figure 5. System process of indirect illuminance learning methods: (a) learning process for luminaire 1,

(b) learning process for luminaire 2.

Assuming that six luminaires are installed in a room where daylight is incident, as shown in Figure 6, the final work plane illuminance (ET1) at a position directly under luminaire 1 can be defined as in Equation (1). The final work plane illuminance is referred to as the sum of the direct illuminance, indirect illuminance, and daylight illuminance. Based on Equation (1), the final work plane illuminance (ETj) of the other points can be calculated using the standardized Equation (2). 


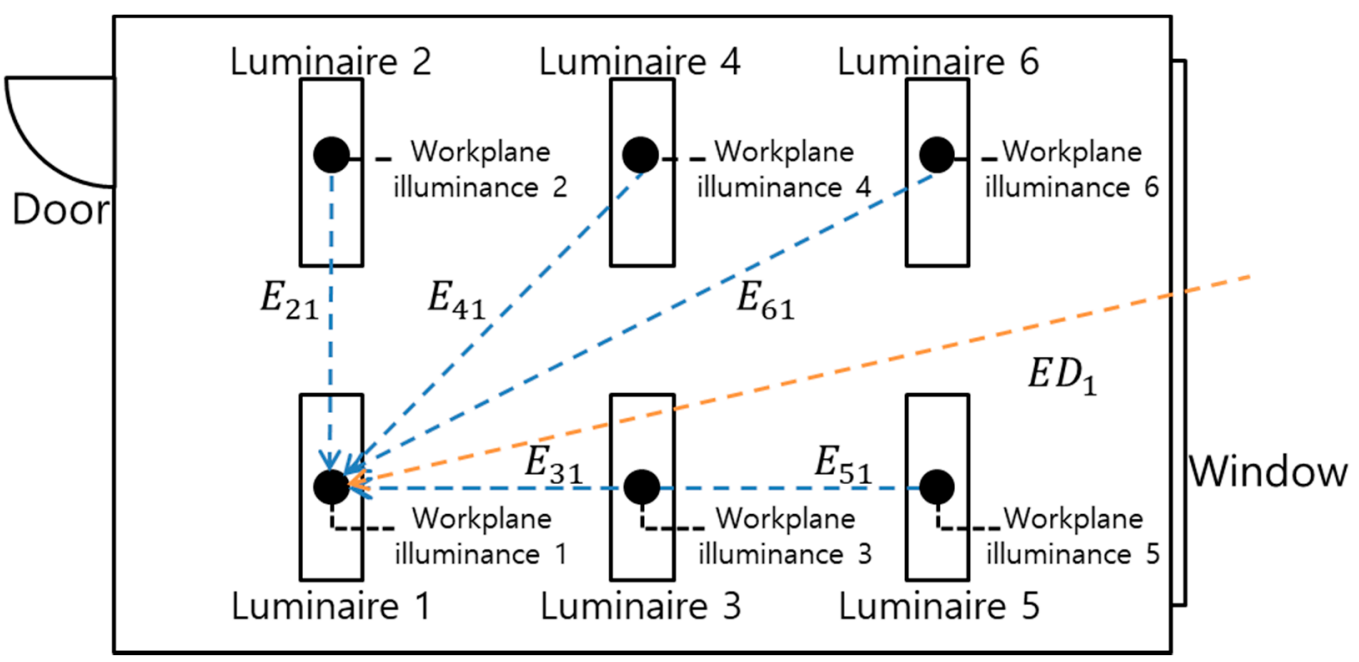

Figure 6. Calculation method of direct and indirect illuminance.

$$
E T_{1}=E D_{1}+E_{11}+E_{21}+E_{31}+E_{41}+E_{51}+E_{61}
$$

$E D_{1}=$ Work plane illuminance at the position directly under the luminaire (1) by daylight; $E_{i j}=$ Work plane illuminance at the position directly under the luminaire $(j)$ by luminaire $(i)$;

$$
E T_{j}=E D_{j}+\sum_{i=1}^{n} E_{i j}
$$

$E T_{j}=$ Final work plane illuminance at the position directly under the luminaire $(j)$;

$E D_{j}=$ Work plane illuminance at the position directly under the luminaire (j) by daylight $n=$ Number of luminaires.

When the target work plane illuminance at each point is set to 500 lx, assuming that ED1 is 200 lx, the required illuminance at a position directly under luminaire 1 (ER1) can be calculated through the following Equation (3). The required illuminance at a position directly under luminaire (j) (ERj) can be defined through Equation (4) based on Equation (3).

$$
\begin{gathered}
\sum_{i=1}^{6} E_{i 1}=E T_{1}-E D_{1}=500 l x-200 l x=300 l x=E R_{1} \\
E_{11}+E_{21}+E_{31}+E_{41}+E_{51}+E_{61}=E R_{1} \\
E_{12}+E_{22}+E_{32}+E_{42}+E_{52}+E_{62}=E R_{2} \\
E_{13}+E_{23}+E_{33}+E_{43}+E_{53}+E_{63}=E R_{3} \\
E_{14}+E_{24}+E_{34}+E_{44}+E_{54}+E_{64}=E R_{4} \\
E_{15}+E_{25}+E_{35}+E_{45}+E_{55}+E_{65}=E R_{5} \\
E_{16}+E_{26}+E_{36}+E_{46}+E_{56}+E_{66}=E R_{6}
\end{gathered}
$$

If the regression equations of the work plane illuminance according to the dimming level when using the indirect illuminance learning method are defined through Equation (5), Equation (4) can be defined as a simultaneous linear equation with six variables, as shown in Equation (6).

$$
E_{i j}=I E_{i j} g\left(L_{j}\right)
$$

$g\left(L_{j}\right)=$ Regression equation of work plane illuminance at the position directly under the luminaire (j) according to the dimming level of luminaire (j); 
$I E_{i j}=$ Proportion of work plane illuminance at the position directly under the luminaire ( $\left.i\right)$ and work plane illuminance at the position directly under the luminaire $(j)$ by luminaire $(i)$.

$$
\begin{aligned}
& I E_{11} g\left(L_{1}\right)+I E_{21} g\left(L_{2}\right)+I E_{31} g\left(L_{3}\right)+I E_{41} g\left(L_{4}\right)+I E_{51} g\left(L_{5}\right)+I E_{61} g\left(L_{6}\right)=E R_{1} \\
& I E_{12} g\left(L_{1}\right)+I E_{22} g\left(L_{2}\right)+I E_{32} g\left(L_{3}\right)+I E_{42} g\left(L_{4}\right)+I E_{52} g\left(L_{5}\right)+I E_{62} g\left(L_{6}\right)=E R_{2} \\
& I E_{13} g\left(L_{1}\right)+I E_{23} g\left(L_{2}\right)+I E_{33} g\left(L_{3}\right)+I E_{43} g\left(L_{4}\right)+I E_{53} g\left(L_{5}\right)+I E_{63} g\left(L_{6}\right)=E R_{3} \\
& I E_{14} g\left(L_{1}\right)+I E_{24} g\left(L_{2}\right)+I E_{34} g\left(L_{3}\right)+I E_{44} g\left(L_{4}\right)+I E_{54} g\left(L_{5}\right)+I E_{64} g\left(L_{6}\right)=E R_{4} \\
& I E_{15} g\left(L_{1}\right)+I E_{25} g\left(L_{2}\right)+I E_{35} g\left(L_{3}\right)+I E_{45} g\left(L_{4}\right)+I E_{55} g\left(L_{5}\right)+I E_{65} g\left(L_{6}\right)=E R_{5} \\
& I E_{16} g\left(L_{1}\right)+I E_{26} g\left(L_{2}\right)+I E_{36} g\left(L_{3}\right)+I E_{46} g\left(L_{4}\right)+I E_{56} g\left(L_{5}\right)+I E_{66} g\left(L_{6}\right)=E R_{6}
\end{aligned}
$$

To calculate the simultaneous equations, the equations in (6) were converted into a matrix, as shown in Equation (7). The inverse roughness ratio matrix of Equation (7) was transformed into Equation (8) by taking the inverse matrix and multiplying both sides. By converting Equation (7) into Equation (8), it is possible to calculate the dimming level that satisfies the required illuminance value of each point.

$$
\begin{gathered}
\left(\begin{array}{llllll}
I E_{11} & I E_{21} & I E_{31} & I E_{41} & I E_{51} & I E_{61} \\
I E_{12} & I E_{22} & I E_{32} & I E_{42} & I E_{52} & I E_{62} \\
I E_{13} & I E_{23} & I E_{33} & I E_{43} & I E_{53} & I E_{63} \\
I E_{14} & I E_{24} & I E_{34} & I E_{44} & I E_{54} & I E_{64} \\
I E_{15} & I E_{25} & I E_{35} & I E_{45} & I E_{55} & I E_{65} \\
I E_{16} & I E_{26} & I E_{36} & I E_{46} & I E_{56} & I E_{66}
\end{array}\right)\left(\begin{array}{l}
g\left(L_{1}\right) \\
g\left(L_{2}\right) \\
g\left(L_{3}\right) \\
g\left(L_{4}\right) \\
g\left(L_{5}\right) \\
g\left(L_{6}\right)
\end{array}\right)=\left(\begin{array}{l}
E R_{1} \\
E R_{2} \\
E R_{3} \\
E R_{4} \\
E R_{5} \\
E R_{6}
\end{array}\right) \\
\left(\begin{array}{l}
g\left(L_{1}\right) \\
g\left(L_{2}\right) \\
g\left(L_{3}\right) \\
g\left(L_{4}\right) \\
g\left(L_{5}\right) \\
g\left(L_{6}\right)
\end{array}\right)=\left(\begin{array}{llllll}
I E_{11} & I E_{21} & I E_{31} & I E_{41} & I E_{51} & I E_{61} \\
I E_{12} & I E_{22} & I E_{32} & I E_{42} & I E_{52} & I E_{62} \\
I E_{13} & I E_{23} & I E_{33} & I E_{43} & I E_{53} & I E_{63} \\
I E_{14} & I E_{24} & I E_{34} & I E_{44} & I E_{54} & I E_{64} \\
I E_{15} & I E_{25} & I E_{35} & I E_{45} & I E_{55} & I E_{65} \\
I E_{16} & I E_{26} & I E_{36} & I E_{46} & I E_{56} & I E_{66}
\end{array}\right) \quad\left(\begin{array}{l}
E R_{1} \\
E R_{2} \\
E R_{3} \\
E R_{4} \\
E R_{5} \\
E R_{6}
\end{array}\right)
\end{gathered}
$$

\section{Evaluation}

\subsection{Test Bed}

To evaluate the accuracy of the work plane illuminance and the energy savings of the daylight responsive dimming system proposed in this study, the DRDS was applied by considering the influence of indirect illuminance on the full-scale test bed, as shown in Figure 7. The size of the test bed was $2750(\mathrm{~W}) \times 6000(\mathrm{~L}) \times 2700(\mathrm{H})[\mathrm{mm}]$, and six luminaires (LED, $1200 \times 300[\mathrm{~mm}], 40 \mathrm{~W}$, with a built-in photosensor) were installed. The test bed was located in Gwangju, a metropolitan city in the Republic of Korea. The azimuth angle of the test bed was $23^{\circ}(\mathrm{SW})$. The work plane illuminance monitoring was conducted after installing an illuminance meter (P1-P6) at the work plane height $(750 \mathrm{~mm})$ directly under each luminaire.
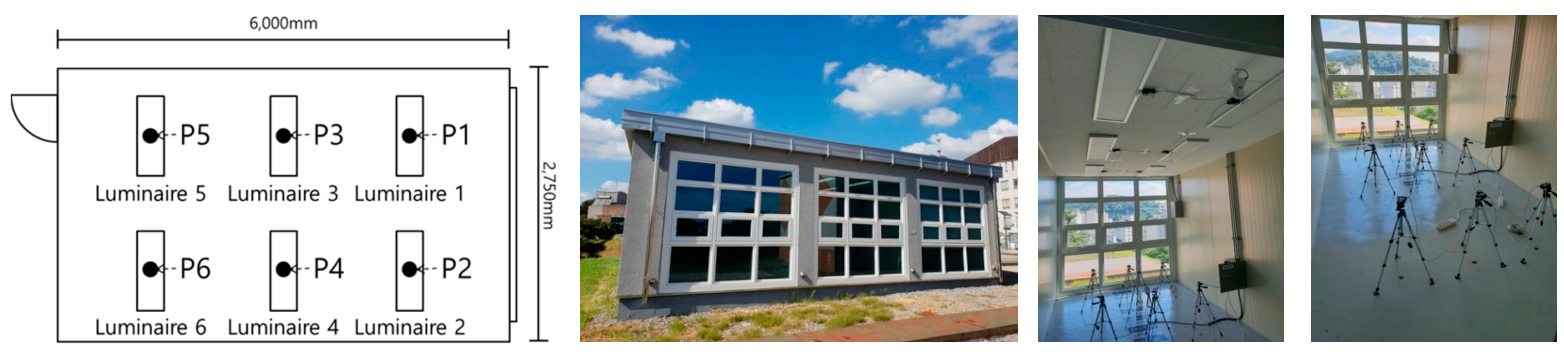

Figure 7. Outline of full-scale test bed. 
Indirect illuminance learning was performed on the full-scale test-bed. The regression equation $\left(g\left(L_{j}\right)\right)$ of work plane illuminance at the position directly under the luminaire $(j)$ according to the dimming level of luminaire ( $j$ ) was analysed as in Figure 8 and Table 1. Also, the proportion of work plane illuminance $\left(I E_{i j}\right)$ at the position directly under the luminaire $(i)$ and work plane illuminance at the position directly under the luminaire $(j)$ by luminaire $(i)$ was analysed as in Table 2 .
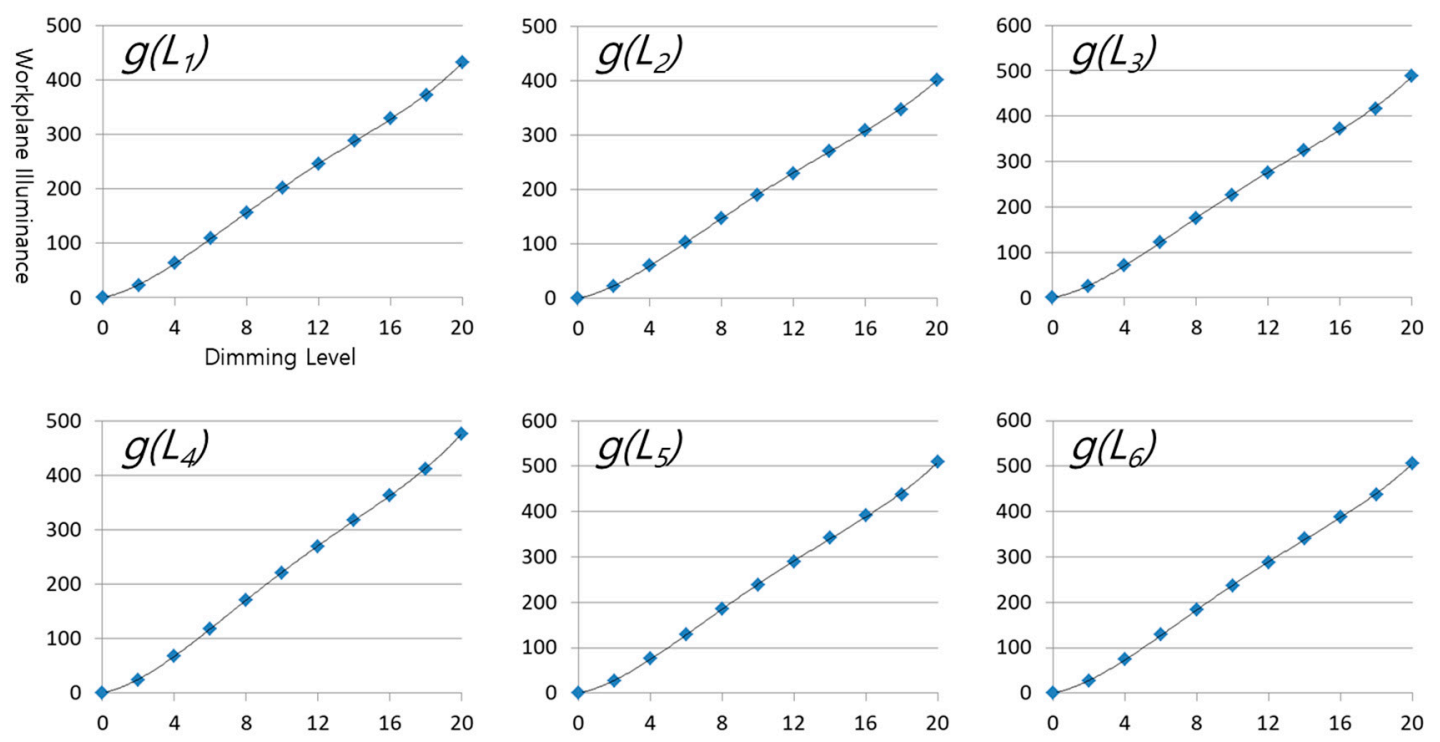

Figure 8. Work plane illuminance according to dimming level.

Table 1. Regression equations $\left(g\left(L_{j}\right)\right)$ of dimming level work plane illuminance.

\begin{tabular}{lccccc}
\hline & $\mathbf{x}^{\mathbf{4}}$ & $\mathbf{x}^{\mathbf{3}}$ & $\mathbf{x}^{\mathbf{2}}$ & $\mathbf{x}$ & $\boldsymbol{R}^{\mathbf{2}}$ \\
\hline$g\left(L_{1}\right)$ & 0.0051 & -0.2112 & 2.9129 & 7.1438 & 0.9999 \\
$g\left(L_{2}\right)$ & 0.0045 & -0.1894 & 2.6403 & 7.0639 & 0.9999 \\
$g\left(L_{3}\right)$ & 0.006 & -0.251 & 3.4595 & 7.2117 & 0.9999 \\
$g\left(L_{4}\right)$ & 0.0055 & -0.2328 & 3.2959 & 7.0318 & 0.9999 \\
$g\left(L_{5}\right)$ & 0.006 & -0.2531 & 3.5007 & 8.2746 & 0.9999 \\
$g\left(L_{6}\right)$ & 0.0058 & -0.2436 & 3.413 & 8.2883 & 0.9999 \\
\hline
\end{tabular}

Table 2. Proportion of indirect work plane illuminance $\left(I E_{i j}\right)$.

\begin{tabular}{ccccccc}
\hline & P1 & P2 & P3 & P4 & P5 & P6 \\
\hline$L_{1}$ & 1 & 0.557 & 0.356 & 0.269 & 0.095 & 0.092 \\
$L_{2}$ & 0.470 & 1 & 0.245 & 0.372 & 0.085 & 0.099 \\
$L_{3}$ & 0.361 & 0.264 & 1 & 0.558 & 0.339 & 0.257 \\
$L_{4}$ & 0.247 & 0.372 & 0.471 & 1 & 0.222 & 0.338 \\
$L_{5}$ & 0.094 & 0.086 & 0.362 & 0.273 & 1 & 0.567 \\
$L_{6}$ & 0.092 & 0.100 & 0.267 & 0.379 & 0.510 & 1 \\
\hline
\end{tabular}

\subsection{Accuracy Evaluation}

The target illuminance accuracy of the proposed dimming control algorithm was evaluated in this study. Therefore, to eliminate errors in the prediction of the work plane illuminance when applying a photosensor attached to the luminaire, the measured work plane illuminance value used as the initial work plane illuminance utilized daylight instead of the predicted value. As shown in Figure 9, the initial work plane illuminance from daylight was measured when all luminaires were turned off. The required dimming level for each luminaire was calculated by inputting the measured initial work plane illuminance value into the dimming control algorithm proposed in this study (step 1). The required dimming level values for each luminaire were input into each luminaire, and all luminaires were 
dimmed automatically. After all of the luminaires were automatically dimmed, the final work plane illuminance, which was a combination of daylight and artificial light, and the power consumption of the luminaires were measured (step 2).
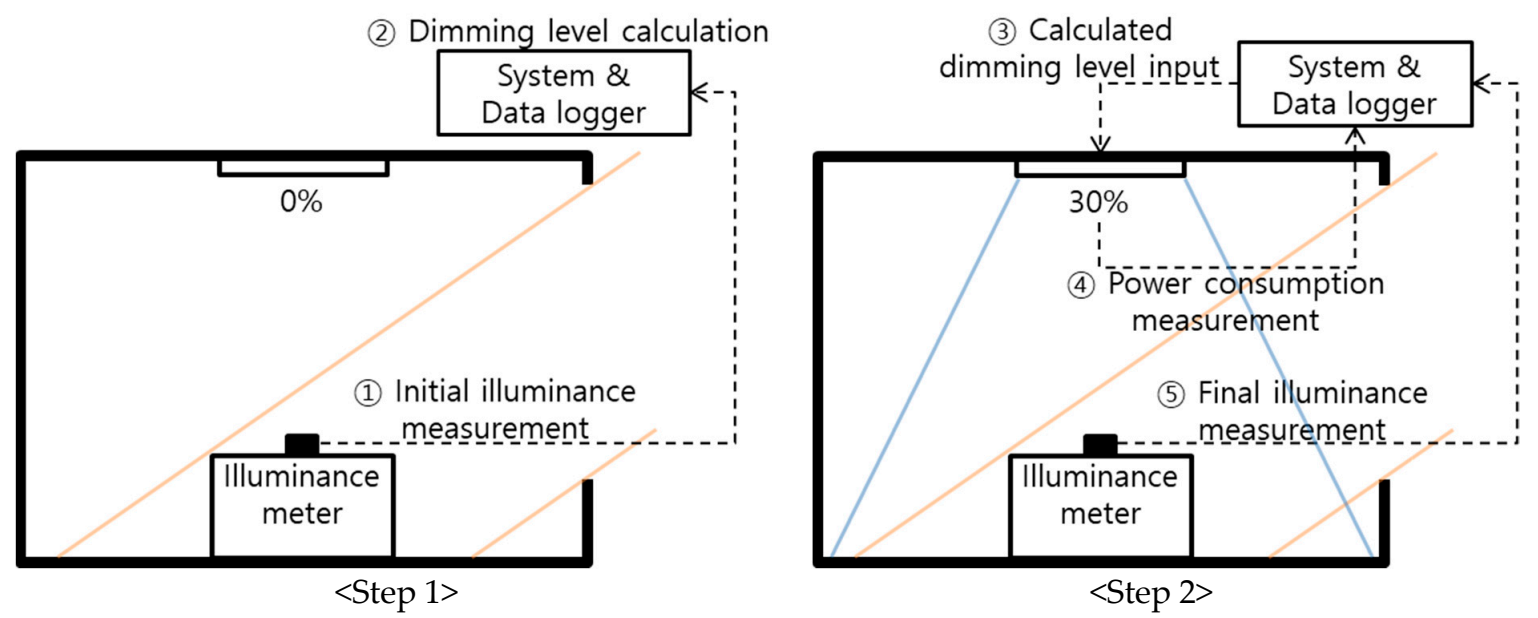

Figure 9. Process for evaluating target illuminance accuracy and energy saving.

Assuming the use of the test bed as an office, the target illuminance was set to 500 lx (Korean standard illuminance), and the evaluation was conducted for 27 days, from 22 June to 18 July 2018 [26]. The daily measurement time was from 9:00 a.m. to 6:00 p.m. at $1 \mathrm{~min}$ intervals. The Republic of Korea has its summer from June to September. The summer in the Republic of Korea experiences a lot of sunshine, which, with the exception of the rainy season, has a long duration.

The accuracy of the target illuminance was calculated by comparing the target illuminance and final measured illuminance. The point at which the work plane illuminance exceeds the target illuminance owing to the initial incident daylight was excluded from the calculation of the accuracy of the target illuminance. For example, if only the initial illuminance by incident daylight of P1 and P2 near the window exceeds the target illuminance, the accuracy and energy saving calculation for all measurement points are not excluded. The accuracy and energy savings for P3 P6 except P1 and P2 were calculated. Figure 10 shows the measurement of the final work plane illuminance of the luminous environment controlled using the proposed dimming control algorithm from 22 June to 18 July 2018, and the results of the analysis of the accuracy of the target illuminance are shown in Figure 11.

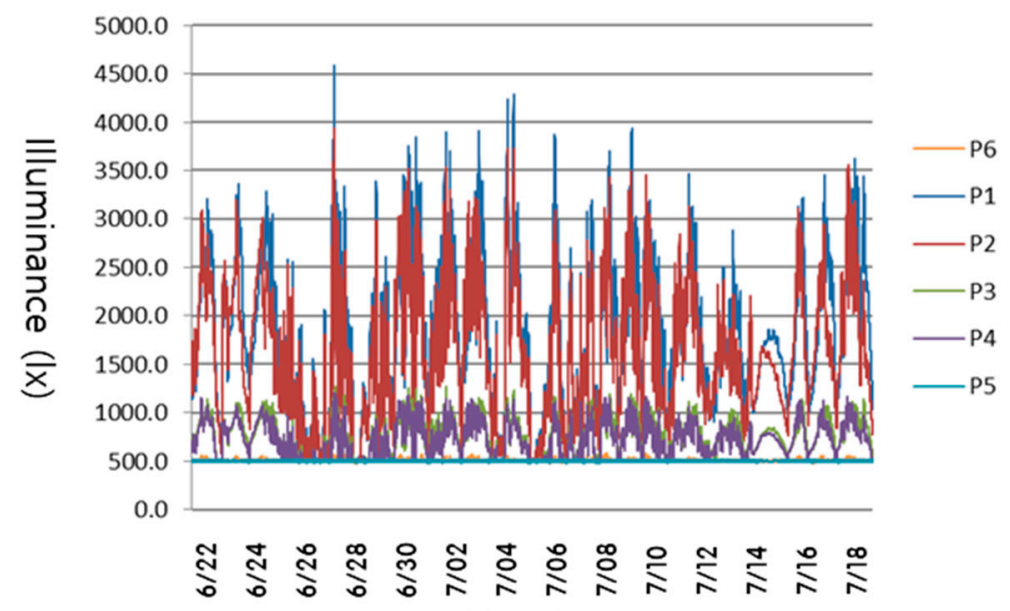

(Date)

Figure 10. Daily measurement results of the final work plane illuminance. 


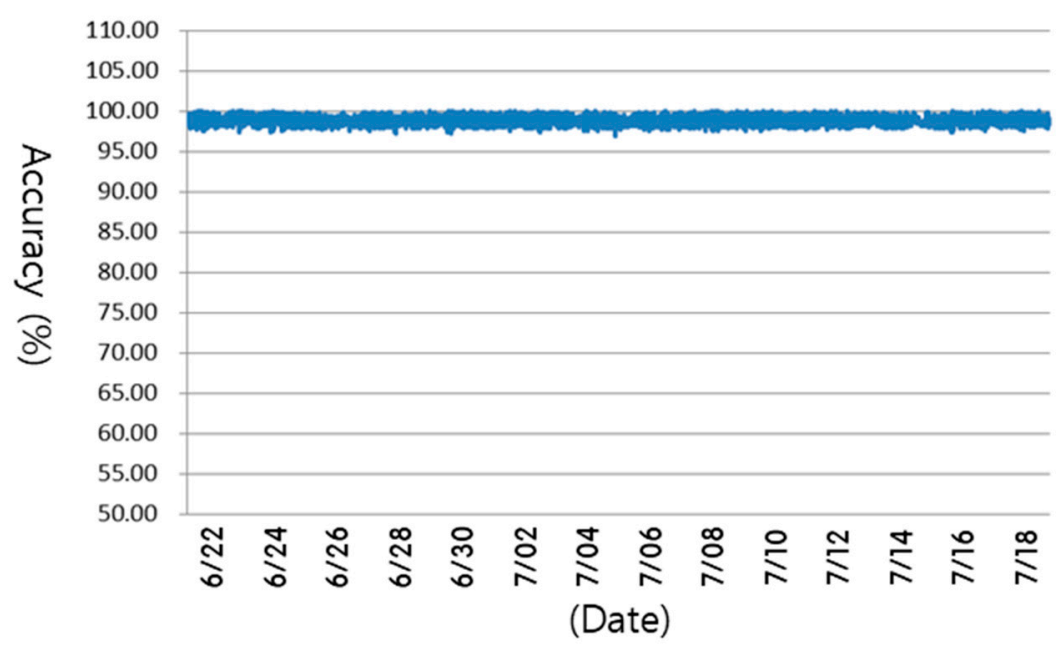

Figure 11. Daily accuracy result of target illuminance.

As shown in Figure 10, the final work plane illuminance of P1 and P2 located near a window was often more than the target illuminance (500 lx). In contrast, the final work plane illuminance of P5 and P6 near a door almost never exceeded $500 \mathrm{~lx}$, and it was found that it remained constant at $500 \mathrm{~lx}$ when using the dimming control algorithm proposed in this study. The accuracy of the target illuminance, shown in Figure 11, is the average accuracy of the target illuminance for all measurement points from P1 to P6. The average accuracy of the target illuminance was $98.9 \%$ (SD 0.5\%), which is quite high. The maximum accuracy was $100 \%$, and the minimum accuracy was $96.9 \%$.

The results of the comparison analysis of the total average target illuminance accuracy with the clearness index $\left(\mathrm{K}_{\mathrm{T}}\right)$ for each day are shown in Figure 12. At a larger clearness index, the sky is without clouds. As shown in Figure 12, the higher the clearness index, the higher the daily average target illuminance accuracy. However, the accuracy was $98.80 \%$ or more regardless of the clearness index.

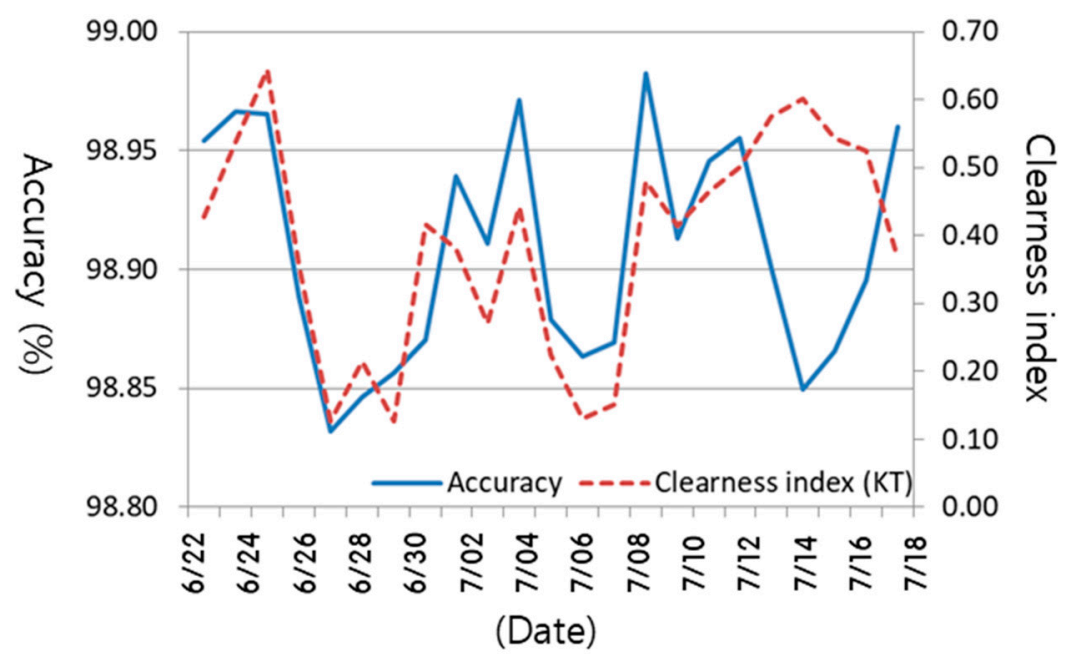

Figure 12. Daily average target illuminance accuracy and clearness index.

The average target illuminance accuracy of points (P1-P6) according to the sky condition was analyzed and the results are shown in Table 3. A clearness index of 0.75 or more was classified as clear sky. If the clearness index was less than 0.75 but more than 0.25 , it was classified as a partly cloudy sky. In addition, if the clearness index was less than 0.25 , it was classified as an overcast sky [27-29]. In the case of clear sky, P1-P4 were excluded from the accuracy calculation because the initial work plane illuminance by daylight of P1-P4 exceeded the target illuminance. In the case of a partly cloudy sky, as 
with the clear sky case, P1 and P2 were excluded from the accuracy calculation. As shown in Table 3, the average target illuminance accuracy was above $98 \%$ in all sky conditions.

Table 3. The average target illuminance accuracy of points (P1-P6) according to the sky condition.

\begin{tabular}{ccccccc}
\hline \multicolumn{7}{c}{$(\mathbf{\% )}$} \\
\hline Sky Condition & P1 & P2 & P3 & P4 & P5 & P6 \\
\hline Clear & - & - & - & - & 99.00 & 98.97 \\
Partly cloudy & - & - & 99.68 & 99.41 & 98.93 & 98.93 \\
Overcast & 98.90 & 99.06 & 98.96 & 99.08 & 98.69 & 98.89 \\
\hline
\end{tabular}

\subsection{Energy Savings Evaluation}

The lighting energy saving ratio was calculated by comparing the lighting energy consumption with the dimming control algorithm proposed in this study and the lighting energy consumption without dimming control. When all of the LED luminaires $(40 \mathrm{~W})$ installed in the full-scale test-bed were turned on $100 \%$, the average work plane illuminance was measured to be about $1000 \mathrm{~lx}$. The power consumption was measured as $104 \mathrm{~W}$ ( $936 \mathrm{Wh}$ per day) by dimming the luminaire to satisfy work plane illuminance $500 \mathrm{~lx}$ of all points from P1 to P6. Therefore, the lighting energy savings waere analyzed based on $104 \mathrm{~W}$ (936 Wh per day). Figure 13 shows the graph of the lighting energy saving ratio.

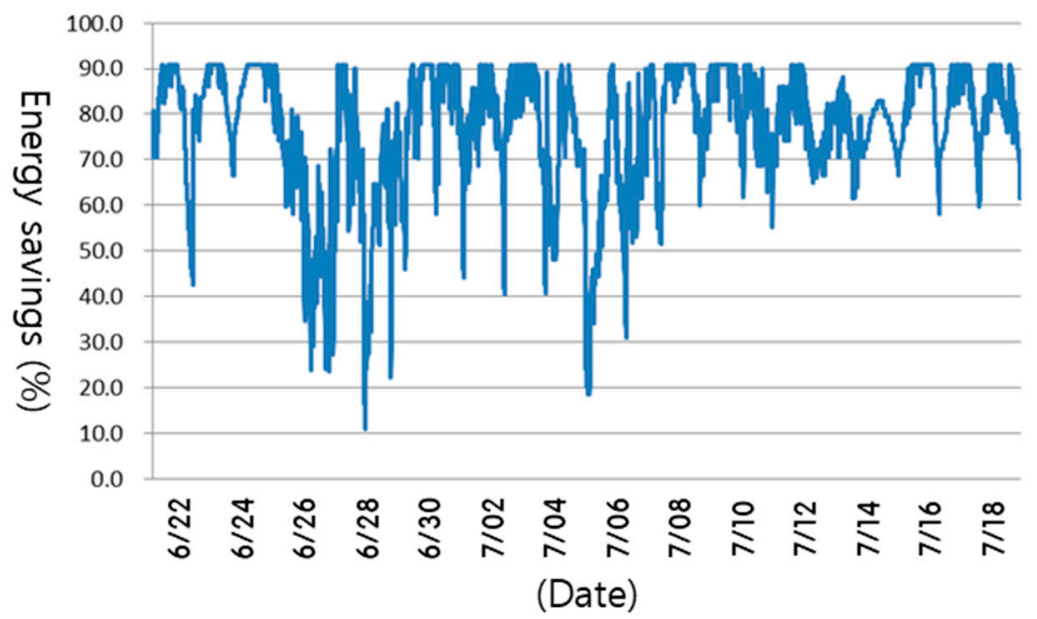

Figure 13. Daily result of lighting energy saving ratio.

As a result of the analysis of the lighting energy saving, the average lighting power consumption was $23.9 \mathrm{~W}$ (210.6 Wh per day), and the average lighting energy saving ratio was $77 \%$. Whereas the amount of lighting energy saving is generally high in the summer, a higher lighting energy saving occurred under a clear sky than under an overcast sky. Because this study was conducted during the summer, the average lighting energy saving ratio for the other seasons and the rainy season could be less than 77\%. Although the initial illuminance of all points exceeded 500 lx, the maximum lighting energy saving ratio was analyzed as $90.1 \%$, and not $100 \%$. This result was caused by the standby power of the luminaire; although all luminaires were turned off, they consumed a total of about $9.6 \mathrm{~W}$ of standby power (1.6 W per luminaire). The maximum lighting energy saving ratio and the average lighting energy saving ratio are expected to increase if a luminaire with little or no standby power is installed. The minimum lighting energy saving ratio was $10.9 \%$, which was demonstrated under a rainy or overcast sky.

The results of the comparison analysis of the total lighting energy saving ratio with the clearness index (KT) for each day were shown in Figure 14. As shown in Figure 14, the higher the clearness 
index, the higher the daily lighting energy saving ratio. The lighting power consumption and lighting energy saving ratio according to the sky condition were analyzed, and the results are shown in Table 4. As can be seen in Table 4, the lighting energy saving ratio was highest with a clear sky. Secondly, the lighting energy saving ratio was higher with a partly cloudy sky. The clear sky and partly cloudy sky did not show a significant difference regarding the lighting energy saving ratio. With an overcast sky, the lighting energy saving ratio was lowest at $64.32 \%$ and showed a great difference from the lighting energy saving ratio with a clear sky and partly cloudy sky.

Table 4. The lighting power consumption and lighting energy saving ratio according to the sky condition.

\begin{tabular}{cccc}
\hline Sky Condition & Average Power Consumption (W) & Daily Power Consumption (Wh) & Savings (\%) \\
\hline Clear & 12.81 & 115.25 & 87.69 \\
Partly cloudy & 16.80 & 151.22 & 83.84 \\
Overcast & 37.11 & 333.96 & 64.32 \\
\hline
\end{tabular}

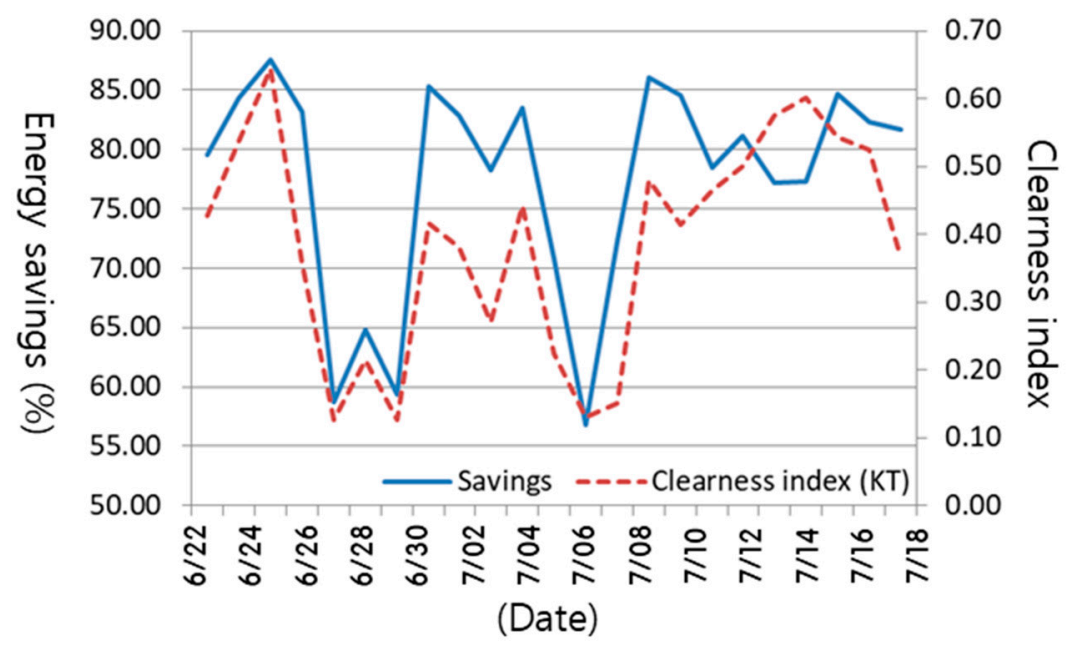

Figure 14. Daily average lighting energy saving ratio and clearness index.

\section{Discussion and Conclusions}

A dimming control algorithm considering the influence of indirect illuminance was developed and was evaluated to verify whether the accuracy of the target illuminance and the lighting energy saving of the DRDS developed in this study could be maintained.

As a result of the accuracy analysis of the target illuminance, the average accuracy was determined to be $98.9 \%$ (SD $0.5 \%$ ). The maximum accuracy was $100 \%$ and the minimum accuracy was $96.9 \%$, which is quite accurate.

As a result of the lighting energy saving ratio analysis, the average lighting power consumption was $23.9 \mathrm{~W}$ (210.6 Wh per day), and the average lighting energy saving ratio was $77 \%$. The maximum lighting energy saving ratio was $90.1 \%$, and the minimum lighting energy saving ratio was $10.9 \%$. This result was caused by the standby power of the luminaire; although all luminaires were turned off, they consumed a total of about $9.6 \mathrm{~W}$ of standby power (1.6 W per luminaire).

The dimming level of the luminaire applied to the dimming control algorithm proposed in this study was applied in 20 steps. If the dimming level is further subdivided, the accuracy of the target illuminance can be improved. In contrast, if the work plane illuminance value predicted through a photosensor attached to the luminaire is used as the initial work plane illuminance by applying daylight instead of the measured value, the accuracy of the target illuminance may be reduced. Therefore, in a future study, an algorithm that increases the accuracy of the work plane illuminance prediction will be developed for a photosensor attached to a luminaire, thereby maximizing the amount of lighting 
energy saving and providing a comfortable luminous environment. Also, to increase practicality, a cost/benefit analysis will be implemented.

Author Contributions: Conceptualization, I.-T.K. and Y.-S.K.; Methodology, Y.-S.K.; Software, H.N.; Validation, I.-T.K., Y.-S.K. and T.H.; Formal Analysis, I.-T.K.; Investigation, Y.-S.K.; Resources, H.N.; Data Curation, I.-T.K.; Writing-Original Draft Preparation, I.-T.K.; Writing-Review \& Editing, T.H.; Visualization, H.N.; Supervision, T.H.; Project Administration, T.H.; Funding Acquisition, T.H.

Funding: This work was supported by the Korea Institute of Energy Technology Evaluation and Planning (KETEP) and the Ministry of Trade, Industry \& Energy (MOTIE) of the Republic of Korea (No. 20182010600110). This work was supported by the Korea Institute of Energy Technology Evaluation and Planning (KETEP) and the Ministry of Trade, Industry \& Energy (MOTIE) of the Republic of Korea (No. 20184010201650).

Conflicts of Interest: The authors declare no conflict of interest.

\section{Nomenclature}

$\begin{array}{ll}\text { DRDS } & \text { Daylight responsive dimming system } \\ E T_{j} & \text { Final work plane illuminance at the position directly under the luminaire }(j) \\ E j & \text { Work plane illuminance at the position directly under the luminaire }(j) \\ E i j & \text { Work plane illuminance at the position directly under the luminaire }(j) \text { by luminaire }(i) \\ E D j & \text { Work plane illuminance at the position directly under the luminaire }(j) \text { by daylight } \\ n & \text { Number of luminaires in the room } \\ E R j & \text { Required illuminance at the position directly under the luminaire }(j) \\ g(L j) & \text { Regression equation of work plane illuminance at the position directly under the luminaire } \\ (\mathrm{j}) & \text { According to the dimming level of luminaire }(j) \\ I E i j & \text { Proportion of work plane illuminance at the position directly under the luminaire }(i) \text { and }\end{array}$

\section{References}

1. Ministry of Land, Infrastructure and Transport. To Cope with Climate Change Zero Energy Building Promotion Plan. In National Building Policy Committee Reporting; Ministry of Land, Infrastructure and Transport (Korea): Sejong, Korea, 2016.

2. Seoul Energy Dream Center. Commercialization of Green Building Remodelling Project for Private Buildings. In Building Energy Seminar; Seoul Energy Dream Center: Seoul, Korea, 2015.

3. Costanzo, V.; Evola, G.; Marletta, L.; Pistone Nascone, F. Application of Climate Based Daylight Modelling to the Refurbishment of a School Building in Sicily. Sustainability 2018, 10, 2653. [CrossRef]

4. Piderit Moreno, M.B.; Labarca, C.Y. Methodology for assessing daylighting design strategies in classroom with a climate-based method. Sustainability 2015, 7, 880-897. [CrossRef]

5. Lee, K.S.; Han, K.J.; Lee, J.W. Feasibility study on parametric optimization of daylighting in building shading design. Sustainability 2016, 8, 1220. [CrossRef]

6. Guan, Y.; Yan, Y. Daylighting Design in classroom based on yearly-graphic analysis. Sustainability 2016, 8, 604. [CrossRef]

7. Mohelníková, J.; Míček, D.; Floreková, S.; Selucká, A.; Dvořák, M. Analysis of Daylight Control in a Chateau Interior. Buildings 2018, 8, 68. [CrossRef]

8. Moazzeni, M.H.; Ghiabaklou, Z. Investigating the influence of light shelf geometry parameters on daylight performance and visual comfort, a case study of educational space in Tehran, Iran. Buildings 2016, 6, 26. [CrossRef]

9. Kim, S.H.; Kim, I.T.; Choi, A.S.; Sung, M. Evaluation of Optimized PV Power Generation an Electrical Energy Savings from the PV Blind-integrated Daylight Responsive Dimming System Using LED Lighting. Sol. Energy 2014, 107, 746-757. [CrossRef]

10. Al-Ashwal, N.T.; Budaiwi, I.M. Energy savings due to daylight and artificial lighting integration in office buildings in hot climate. Int. J. Energy Environ. 2011, 2, 999-1012.

11. Fernandes, L.L.; Lee, E.S.; Ward, G. Lighting energy savings potential of split-pane electrochromic windows controlled for daylighting with visual comfort. Energy Build. 2013, 61, 8-20. [CrossRef] 
12. Caicedo, D.; Pandharipande, A.; Willems, F.M. Daylight-adaptive lighting control using light sensor calibration prior-information. Energy Build. 2014, 73, 105-114. [CrossRef]

13. Yoo, S.; Kim, J.; Jang, C.Y.; Jeong, H. A sensor-less LED dimming system based on daylight harvesting with BIPV systems. Opt. Express 2014, 22, A132-A143. [CrossRef] [PubMed]

14. Gentile, N.; Dubois, M.C. Field data and simulations to estimate the role of standby energy use of lighting control systems in individual offices. Energy Build. 2017, 155, 390-403. [CrossRef]

15. Nagy, Z.; Yong, F.Y.; Frei, M.; Schlueter, A. Occupant centered lighting control for comfort and energy efficient building operation. Energy Build. 2015, 94, 100-108. [CrossRef]

16. Gentile, N.; Laike, T.; Dubois, M.C. Lighting control systems in individual offices rooms at high latitude: Measurements of electricity savings and occupants' satisfaction. Sol. Energy 2016, 127, 113-123. [CrossRef]

17. Kaminska, A.; Ożadowicz, A. Lighting Control Including Daylight and Energy Efficiency Improvements Analysis. Energies 2018, 11, 2166. [CrossRef]

18. Yun, G.Y.; Kim, H.; Kim, J.T. Effects of occupancy and lighting use patterns on lighting energy consumption. Energy Build. 2012, 46, 152-158. [CrossRef]

19. Pandharipande, A.; Caicedo, D. Daylight integrated illumination control of LED systems based on enhanced presence sensing. Energy Build. 2011, 43, 944-950. [CrossRef]

20. Wang, Z.; Tan, Y.K. Illumination control of LED systems based on neural network model and energy optimization algorithm. Energy Build. 2013, 62, 514-521. [CrossRef]

21. Choi, H.; Hong, S.; Choi, A.; Sung, M. Toward the accuracy of prediction for energy savings potential and system performance using the daylight responsive dimming system. Energy Build. 2016, 133, 271-280. [CrossRef]

22. Yun, S.I.; Kim, K.S. Sky Luminance Measurements Using CCD Camera and Comparisons with Calculation Models for Predicting Indoor Illuminance. Sustainability 2018, 10, 1556. [CrossRef]

23. Park, B.C.; Choi, A.S.; Jeong, J.W.; Lee, E.S. Performance of integrated systems of automated roller shade systems and daylight responsive dimming systems. Build. Environ. 2011, 46, 747-757. [CrossRef]

24. Parise, G.; Martirano, L. Daylight impact on energy performance of internal lighting. IEEE Trans. Ind. Appl. 2013, 49, 242-249. [CrossRef]

25. Ul Haq, M.A.; Hassan, M.Y.; Abdullah, H.; Rahman, H.A.; Abdullah, M.P.; Hussin, F.; Said, D.M. A review on lighting control technologies in commercial buildings, their performance and affecting factors. Renew. Sustain. Energy Rev. 2014, 33, 268-279. [CrossRef]

26. Korean Standards Association. Korean Industrial Standards, KS A3011, KS Recommended Levels of Illumination; KSA: Seoul, Korea, 1998.

27. Duffie, J.A.; Beckman, W.A. Solar Engineering of Thermal Processes; John Wiley \& Sons: Hoboken, NJ, USA, 2013.

28. Park, B.C.; Choi, A.S.; Jeong, J.W.; Lee, E.S. A Preliminary Study on the Performance of Daylight Responsive Dimming Systems with Improved Closed-Loop Control Algorithm. Leukos 2011, 8, 41-59.

29. Jeong, K.Y.; Choi, A.S.; Sung, M. A mock-up study for validation of an improved control algorithm for automated roller shade. Indoor Built Environ. 2016, 25, 17-28. [CrossRef]

(C) 2018 by the authors. Licensee MDPI, Basel, Switzerland. This article is an open access article distributed under the terms and conditions of the Creative Commons Attribution (CC BY) license (http://creativecommons.org/licenses/by/4.0/). 